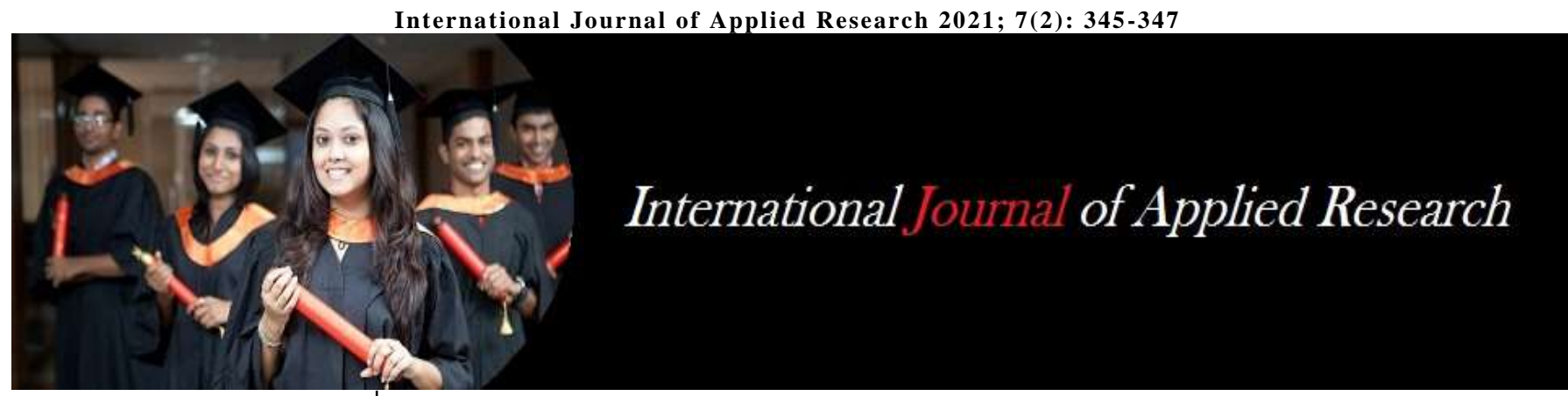

ISSN Print: 2394-7500 ISSN Online: 2394-5869 Impact Factor: 8.4 IJAR 2021; 7(2): 345-347 www.allresearchjournal.com Received: 14-11-2020 Accepted: 02-01-2021

Shweta

M. Sc. Nursing Tutor, St. Stephen's Hospital College of Nursing, New Delhi, India

Corresponding Author: Shweta

M. Sc. Nursing Tutor, St. Stephen's Hospital College of Nursing, New Delhi, India

\section{A study to assess the effectiveness of the structured teaching programme on the knowledge of health care personnel regarding bio medical waste management in various department of selected government hospital in Delhi}

\section{Shweta}

DOI: https://doi.org/10.22271/allresearch.2021.v7.i2f.8302

\begin{abstract}
Background: Bio medical waste (BMW) collection and proper disposal has become a significant concern for both the medical and general community. Effective management of biomedical waste is not only a legal necessity but also a social responsibility.

Material and Method: The evaluative research approach was considered to be most appropriate to measure the effectiveness of the structured teaching programme on the knowledge regarding Bio Medical Waste Management Setting of the study was selected Government Hospital in Delhi. In the present study, the sample comprised of 30 health care personnel in various department which include 10 participants from each department i.e. doctors, nursing officer, nursing aids. Random sampling technique was adopted to select the samples.

Result: The mean post-test knowledge score of health care professional is higher than the pre-test score. Hence the teaching programme was found to be effective in improving the knowledge of health care personnel on Bio Medical Waste Management.

Conclusion: On the basis of the findings of study the following conclusion were drawn that Health care personnel was having less knowledge regarding bio medical waste management. The PowerPoint Presentation was found to be effective in increasing the knowledge of the health care personnel regarding bio medical waste management.
\end{abstract}

Keywords: Bio medical waste management, nursing officer, nursing aids

\section{Introduction}

'Bio-medical waste' (BMW) means any solid and/or liquid waste including its container and any intermediate product, which is generated during the diagnosis, treatment or immunization of human beings or animals or in research pertaining thereto or in the production or testing thereof ${ }^{[1]}$.

The improper management and lack of disposal technique of the domestic waste pollutes to the environment. It affects the water bodies. It also changes the physical, chemical and biological properties of the water bodies. Uncollected waste is scattered everywhere and reaches to the water bodies through run-off as well as it percolates to underground water. The toxics contain in the waste, contaminates water. It also makes soil infertile and decrease the agricultural productivity ${ }^{[2]}$.

Due to uncollected waste and improper disposal techniques drains also get clogged which lead to mosquitoes by which various diseases like malaria, chickun-gunya, viral fever, dengue etc. arise and affect the health of people adversely ${ }^{[3]}$.

Poor Domestic waste management also displays an ugly scenario of the environment. This can affect the tourism industry, as the tourist may not get attracted to visit the country ${ }^{[4]}$.

The awareness regarding biomedical waste management is very less among health care personnel. Thus all the hospital care personnel are at risk to get many fatal infections like HIV, HBV, HCV and injuries by these infectious materials ${ }^{[4]}$. The health care personnel are not aware of the process of biomedical waste management which includes collection, segregation, transportation and disposal of waste. 
They are not aware of the colour coding used in the biomedical waste management also. Many of the health care personnel are not aware of the legal issues because they are not aware of the Bio-medical Waste (Management and Handling) law $1998^{[5]}$.

Medical waste is infectious and hazardous. It poses serious threats to environmental health and requires scientific treatment and management prior to its final disposal. The problem is growing with an ever-increasing number of hospitals, clinics and diagnostic laboratories ${ }^{[6]}$.

Wastes generated from health care facilities are varied in nature, ranging from ordinary organic waste to highly hazardous liquid and solid waste. The part of hospital that has the potential to spread infections/ disease has been termed as Bio-Medical Waste. The total hospital waste generated, approximately 25 percent is hazardous, 75 percent is general (non-risk) waste. The composition of the waste differs with respect to its size, nature of services, and location. The hospital waste includes plastics and PVC, cotton and bandages, syringe and needles, glass, food material and liquid waste, etc. ${ }^{[7]}$

Bio medical waste has become a serious health hazard in many countries, including India. Careless and indiscriminate disposal of this waste by health care establishments and research institutions can contribute to the spread of serious diseases such as Hepatitis and AIDS among those who handle it and also among the general public ${ }^{[8]}$.

\section{Materials and Methods}

Study design: An exploratory design was selected for the study.

Study setting: Setting of the study was selected Government Hospital in Delhi.

Sampling technique: In the present study, the sample comprised of 30 health care personnel in various department which include 10 participants from each department i.e. doctors, nursing officer, nursing aids. Convenient sampling technique was adopted to select the samples.

After obtaining formal permission was obtained from the Head of Department, selected Government Hospital in Delhi. A written informed consent was taken from the subjects, concerned and were assured that anonymity of subjects and confidentiality of information would be maintained. The final study was conducted in selected Government Hospital in Delhi. The subjects comprise of 30 health care personnel in various department which include 10 participants from each department i.e. doctors, nursing officer, nursing aids. The data was collected using structured questionnaire.

\section{Inclusion criteria}

- Only 30 Health care personnel (10 doctors, 10 nursing officers, 10 nursing aids)

- Those who are present at the time of study.

\section{Procedure methodology}

After written informed consent was obtained. Selfintroduction was given, the purpose and the importance of the study was explained. Pre-test was taken after administering structured questionnaire individually; 30 minutes was spent with each respondent and the data was collected. Immediately PowerPoint presentation was given on Bio Medical Waste management. After 7 days post test was conducted. Data was evaluated through statistical method.

\section{Statistical analysis}

Data was analyzed using SPSS version 20. Descriptive and inferential statistics were used for data analysis. The data was analyzed by calculating the mean, standard deviation.

\section{Results}

Table 1: Mean Difference of Pre-Teaching Knowledge \& Post-Teaching Knowledge Score of the Samples Regarding Bio Medical Waste Management

\begin{tabular}{|c|c|c|c|c|c|c|c|}
\hline \multicolumn{3}{|c|}{ Aspect wise mean pre test and post test knowledge on bio medical waste management } \\
\hline \multirow{3}{*}{ No. } & \multirow{3}{*}{ Knowledge aspect } & \multicolumn{7}{|c|}{ Respondent's knowledge } \\
\cline { 3 - 7 } & & \multicolumn{2}{|c|}{ Pre test } & \multicolumn{2}{c|}{ Post test } & \multicolumn{2}{c|}{ Enhancement } \\
\cline { 3 - 7 } & & Mean & SD & Mean & SD & Mean & SD \\
\hline 1. & Doctor & 9.6 & 1.90 & 13.9 & 2.13 & 4.3 & 2.71 \\
\hline .2. & Nursing officer & 10.3 & 1.06 & 14.4 & 1.77 & 4.1 & 1.37 \\
\hline 3. & Nursing aids & 9.3 & 0.95 & 15 & 1.15 & 5.7 & 1.41 \\
\hline
\end{tabular}

\section{Sample characteristics}

\section{Distribution according to percentage of demographic variables}

- According to designation, (33.3\%) health care personnel were doctors, $(33.3 \%)$ health care personnel were nursing officers and $(33.3 \%)$ health care personnel were nursing aids.

- According to year of experience, $(40 \%)$ of health care personnel were having more than 10 years of experience followed by $(30 \%)$ of health care personnel were having 0-5 years of experience and 5-10 years of experience both.

- According to attending in-service education class regarding Bio Medical Waste management in past 6 months, maximum no. of health care personnel $(56.7 \%)$ has not attended class and $(43.3 \%)$ health care personnel have attended class.

- According to thought of following Bio Medical Waste management criteria in setting, maximum no. health care personnel $(83.3 \%)$ agreed an $(16.7 \%)$ health care personnel disagreed.

- According to usefulness of Bio Medical Waste management criteria in setting, $(100 \%)$ health care personnel agreed.

\section{Distribution according to mean score}

- Highest pre-test mean score (10.3) was of nursing officers, followed by (9.6) was of doctors and the lowest score (9.3) was of nursing aids. 
- Highest post-test mean score (15) was of nursing aids, followed by (14.4) was of nursing officers and the lowest score (13.9) was of doctors.

- Highest enhancement mean score (5.7) was of nursing aids, followed by (4.3) was of doctors and the lowest score (4.1) was of nursing officers.

\section{Discussion}

The study aimed to assess the effectiveness of the structured teaching programme on the knowledge of health care personnel regarding bio medical waste management in various department of selected government hospital.

1. To assess the socio demographic variables of health care personnel's according to designation, (33.3\%) health care personnel were doctors, $(33.3 \%)$ health care personnel were nursing officers and $(33.3 \%)$ health care personnel were nursing aids. Maximum no. of health care personnel $(40 \%)$ were having more than 10 years of experience $(56.7 \%)$ health care personnel were attended in-service education class regarding Bio Medical Waste management in past 6 months, $(83.3 \%)$ health care personnel agreed to thought of following Bio Medical Waste management criteria in setting, (100\%) health care personnel agreed to usefulness of Bio Medical Waste management criteria in setting.

2. To assess the knowledge of health care professional regarding Bio Medical Waste management.

According to the pre-test knowledge highest mean attitude score (10.3) was of nursing officers, followed by (9.6) was of doctors and the lowest score (9.3) was of nursing aids, highest post-test mean score (15) was of nursing aids, followed by (14.4) was of nursing officers and the lowest score (13.9) was of doctors

\section{Conclusion}

Researchers has taken this study to assess the knowledge of health care personnel regarding Bio Medical Waste management in selected hospital in Delhi. Data was collected among 30 health care personnel (10 doctors, 10 nursing aids, 10 nursing officers). Descriptive and inferential statistics were used for data analysis.

\section{References}

1. Sharma AK. Biomedical Waste (Management and Handling) Rules. First edition. Bhopal. Suvidha Law House 12.

2. Pathan AKB. Domestic Waste: Hazard to the Life and Its Effect on Human Being Lawyer and LLM. student From Nagpur [online] 2006. [cited on 2009Nov20];Available from: URL:http://azim_pthan@legalserviceindia.com

3. Kaundal R, Sharma A. Problems of Household Waste Disposal Department of Family Resource Management, College of Home Science, CSK HPKV, Palampur 176 062, Himachal Pradesh, India J. Hum. Ecol [serial online]. [Cited on 2009Nov20] 2007;21(3):199-201. Available from: URL:http://www.google.com

4. Students of Namilyango College. Domestic waste management in Kampala city. [Online] 2005. [cited on 2009 Nov 20]; Available from: URL:http://www.angelfire.com/nanicol/waste.html

5. WHO. Safe management of wastes from health care activities 1995, 25-26.
6. Park K. Parks text book of preventive and social medicine, $16^{\text {th }}$ edition, M/S Banarsidas Bhanot 30-32.

7. Health system management project, biomedical waste 2008.

8. Rao TH. Hospital Waste Management Awareness and Practices, Bella Vista, Hyderabad India 2008, 297-303. 